\title{
The conundrum of the Epstein-Barr virus-associated gastric carcinoma in the Americas
}

\author{
Gonzalo Carrasco-Avino ${ }^{1,2}$, Ismael Riquelme ${ }^{3,4}$, Oslando Padilla $^{5}$, Miguel Villaseca ${ }^{4}$, \\ Francisco R. Aguayo ${ }^{1,6}$ and Alejandro H. Corvalan ${ }^{1,7,8}$ \\ ${ }^{1}$ Advanced Center for Chronic Diseases (ACCDIS), Pontificia Universidad Catolica de Chile, Santiago, Chile \\ ${ }^{2}$ Department of Pathology, Faculty of Medicine, Universidad de Chile, Santiago, Chile \\ ${ }^{3}$ Scientific and Technological Bioresource Nucleus (BIOREN), Universidad de la Frontera, Temuco, Chile \\ ${ }^{4}$ Department of Pathology, Universidad de la Frontera, Temuco, Chile \\ ${ }^{5}$ Department of Public Health, School of Medicine, Pontificia Universidad Catolica de Chile, Santiago, Chile \\ ${ }^{6}$ Department of Basic and Clinical Oncology, Faculty of Medicine, Universidad de Chile, Santiago, Chile \\ ${ }^{7}$ UC-Center for Investigational Oncology (CITO), Pontificia Universidad Catolica de Chile, Santiago, Chile \\ ${ }^{8}$ Department of Hematology and Oncology, School of Medicine, Pontificia Universidad Catolica de Chile, Santiago, Chile \\ Correspondence to: Alejandro H. Corvalan, email: corvalan@med.puc.cl
}

Keywords: gastric cancer, Epstein-Barr virus, americas, molecular classification, phylogeographic diversity

Received: December 20, $2016 \quad$ Accepted: May 29, $2017 \quad$ Published: June 15, 2017

Copyright: Carrasco-Avino et al. This is an open-access article distributed under the terms of the Creative Commons Attribution License 3.0 (CC BY 3.0), which permits unrestricted use, distribution, and reproduction in any medium, provided the original author and source are credited.

\section{ABSTRACT}

Epstein-Barr virus-associated gastric carcinoma shows a higher prevalence in the Americas than Asia. We summarize all studies of Epstein Barr virus-associated gastric carcinoma in the Americas, focusing on host characteristics, environmental associations and phylogeographic diversity of Epstein-Barr virus strains. In the Americas, the prevalence of Epstein Barr virus-associated gastric carcinoma is $11.4 \%$, more frequent in males and portray predominantly diffuse-type histology. EBERs, EBNAs, BARTs and LMP are the highest expressed genes; their variations in healthy individuals may explain the phylogeographic diversity of Epstein-Barr virus across the region. Gastric cancer cases harbor exclusively the western genotype (subtype $D$ and kept Xho I site), suggesting a disrupted co-evolution between the pathogen and its host. Epstein-Barr virus-associated gastric carcinoma molecular subtype cases from The Cancer Genome Atlas display PIK3CA gene mutations, amplification of JAK2, PD-L1 and PD-L2 and CpG island methylator phenotype, leading to more extensive methylation of host and viral genomes than any other subtypes from the study. Environmental conditions include negative- and positive- associations with being firstborn child and smoking, respectively. A marginal association with $\mathrm{H}$. pylori has also been reported. Lymphoepithelioma-like carcinoma is associated with Epstein Barr virus in $80 \%-86 \%$ of cases, most of which have been included as part of Epstein Barr virus-associated gastric carcinoma series (prevalence 1.1\%-7.6\%). Whether these cases represent a variant of Epstein-Barr virus-associated gastric carcinoma is discussed. We propose novel research strategies to solve the conundrum of the high prevalence of Epstein-Barr virus-associated gastric carcinoma in the Americas.

\section{INTRODUCTION}

Gastric cancer is the fifth most common malignancy and the third leading cause of cancer death in both sexes worldwide, accounting for 951,000 new cases and 723,000 deaths in 2012 [1]. As with other infection-related cancers, an increasing proportion of gastric cancer falls on lowand middle-income countries including the Americasparticularly, Central and South America [2]. The highest prevalence rates have been observed in countries from 
the pacific coast such as Chile, Costa Rica, Colombia, and Ecuador (i.e. $>20$ cases per 100000 men); whereas the lowest rates have been observed in the U.S., Canada, Argentina, Cuba, and Puerto Rico (<4/100000) [2]. Due to the growth and aging of the population, gastric cancer is expected to escalate from the fifteenth to the tenth cause of death in all-cause mortality within the region in the next 15 years [3].

In this scenario, novel molecular classifications and meta-analyses have identified Epstein-Barr virus (EBV) as a distinct etiological agent for gastric cancer [4-7]. A striking feature of EBV-associated gastric carcinoma (EBVaGC) is the high prevalence observed in the Americas as compared with Asia (OR: 1.7, 95\% CI:1.1-2.7) [7]. The main purposes of this review are to describe the clinical, molecular and environmental characteristics of EBVaGC in the Americas, and to propose novel research strategies for the exploration of this conundrum.

\section{EBV-associated gastric carcinoma in the Americas}

EBVaGC in the Americas was first reported by Shibata and coworkers [8]. These authors identified 22 of 138 (16\%) EBV-positive cases in U.S. GC cases by in-situ hybridization of EBV-encoded small RNAs (EBERs) in tumor samples. In positive cases, EBERs were expressed exclusively in gastric tumor cells. No EBV sequences were detected in the surrounding lymphocytes or precancerous lesions, such as chronic gastritis or intestinal metaplasia. In addition, EBVaGCs were more frequently observed in males than females $(p=0.007)$. Subsequent studies by Gulley and coworkers [9] and Vo and coworkers [10], identified 11 of $95(12 \%)$ and 9 of $43(20 \%)$ EBV-positive GC cases, respectively, in Mexican descendants living in the U.S. However, only Vo et al. [10] confirmed male predominance $(p=0.01)$. Later, Herrera-Goepfert et al. [11] identified 24 of $330(7.3 \%)$ EBV-positive cases in Mexico City. In this series, no male predominance was confirmed. Interestingly, all cases were of diffuse-type histology. In Colombia, Carrascal et al., [12] examined 178 consecutive gastric carcinoma cases identifying $23(13 \%)$ cases of EBVaGCs. In this study, EBVaGCs were most often detected in males $(p=0.004)$, and located predominantly on the non-antrum stomach $(p=0.009)$. Koriyama et al., [13] examined 151 cases from Brazil, detecting 11.2\% of EBVaGC. Although EBVaGC was most frequent among males $(p=0.047)$, Lopes and coworkers [14] did not confirm this finding in a posterior study. Another series consisting of 254 gastric cancer cases from Japanese descendants living in Peru were evaluated by Yoshiwara et al., [15], identifying only 3.9\% EBVaGC (10 cases). In this series, no evident predominance by gender or histological subtype were detected. Finally, in Chile, Corvalan and coworkers [16] detected 31 of 185 $(16.8 \%)$ EBV-positive gastric cancer cases. In this series, predominance of diffuse-type histology $(p<0.001)$ and non-antrum location $(p=0.01)$ were the most significant findings. No reports of EBVaGC have been described in other American countries. A consolidated overview of EBVaGC in the Americas is shown in Table 1. The metaanalytic estimated prevalence of EBV positivity in the region was $11.49 \%$ (95\% $\mathrm{CI}=8.46$ to 15.43$)$, with high heterogeneity among studies $\left(\mathrm{I}^{2}=73.3 \% ; p<0.001\right)$. Interestingly, heterogeneity for predominant sex, location and histology was low (I2=16.5\% $[p=0.35] ; 0 \%[p=0.68]$ and $33.7 \%[p=0.16]$, respectively). Univariate analysis shows male predominance $(p<0.001)$, non-antrum location $(p<0.001)$ and diffuse-type histology $(p<0.001)$ as the most significant features of EBVaGC in the Americas. Odds-ratio estimated for male predominance and diffuse histology were 2.19 (95\% CI: 1.35-3.56) and 2.16 (95\% CI: 1.33-3.49), respectively (see Figure 1 and Figure 2).

\section{Role of viral factors in the pathogenesis of EBV-associated gastric carcinoma}

\section{Overview of viral machinery of EBV}

$\mathrm{EBV}$ is a $175 \mathrm{Kbp}$ double-stranded lineal DNA virus that belongs to the gamma herpesvirus family [17]. The main feature of these viruses is the establishment of persistent latent infections and the possibility of viral reactivation under determined conditions. Thus, the virus persists throughout life without any possibility of clearance [17]. The sequence of events leading to a latent infection are: i) virus entry to cells that express the CD21 receptor, ii) virus transportation to the nucleus, iii) genome circularization and chromatinization, iv) transcription of latency-associated genes and v) repression of lytic cycle genes [18]. In the neoplastic process, the virus remains in a latent stage in every tumor cell, repressing the expression of genes involved in viral replication. However, virus integration into the host genome almost never occurs, and the EBV genome is always found in an episomal form within the cell nucleus. However, there is one report in The Cancer Genome Atlas (TCGA) network showing one gastric cancer case with evidence of integration of the EBV genome into the human genome, in which multiple independent RNAseq reads revealed a fusion transcript predicted to join the first 20 amino acids of the human plasminogen receptor (PLGRKT, alias C9orf46) to almost the entire coding sequence of the early lytic EBV gene BHLF1 (alias EA-D) [19]. The expression patterns of some specific EBV genes define the type of latency into the cells (for review see [20]). In EBVaGC the virus shows a type I/II latency, where the most relevant genes associated with the pathogenesis are: EBV encoded RNAs (EBERs), the EBV Nuclear Antigens (EBNAs), the BamH1-A rightward transcripts (BARTs) and, apparently, some Latent Membrane proteins (LMP) genes are actively expressed [17]. The EBER-1 and -2 genes are the most abundant small non-coding RNAs that 
Table 1: EBV-associated gastric cancer in Latin America

\begin{tabular}{|c|c|c|c|c|c|c|c|c|c|c|c|}
\hline \multirow[b]{2}{*}{ Authors } & \multirow[b]{2}{*}{ Country } & \multirow[b]{2}{*}{ Frequency } & \multicolumn{3}{|c|}{ Sex } & \multicolumn{3}{|c|}{ Histology } & \multicolumn{3}{|c|}{ Location } \\
\hline & & & Male & Female & $p$ value & Intestinal & Diffuse & $p$ value & Antrum & $\begin{array}{c}\text { Non- } \\
\text { antrum }\end{array}$ & $p$ value \\
\hline $\begin{array}{l}\text { Shibata et al. } \\
\text { (1992) }\end{array}$ & U.S. & $22 / 138(16 \%)$ & $21 / 99$ & $1 / 39$ & 0.007049 & $15 / 95$ & $7 / 43$ & 1 & ND & ND & ND \\
\hline Vo et al. (2002) & $\begin{array}{l}\text { Mexican } \\
\text { descendants in the } \\
\text { U.S. }\end{array}$ & $9 / 43(20.9 \%)$ & $9 / 32$ & $0 / 11$ & 0.012667 & ND & ND & ND & ND & ND & ND \\
\hline $\begin{array}{l}\text { Gulley et al. } \\
(1996)\end{array}$ & $\begin{array}{l}\text { Mexican } \\
\text { descendants in the } \\
\text { U.S. }\end{array}$ & $11 / 95(12 \%)$ & $9 / 50$ & $2 / 33$ & 0.116414 & $4 / 47$ & $7 / 37$ & 0.160373 & ND & ND & ND \\
\hline $\begin{array}{l}\text { Herrera-Goepfert } \\
\text { et al. (2005) }\end{array}$ & Mexico & $24 / 330(7.3 \%)$ & $13 / 173$ & $11 / 157$ & 0.859116 & $4 / 141$ & $20 / 189$ & 0.007012 & $16 / 192$ & $8 / 156$ & 0.24061 \\
\hline $\begin{array}{l}\text { Carrascal et al } \\
.2003\end{array}$ & Colombia & $23 / 178(13 \%)$ & $19 / 108$ & $4 / 69$ & 0.022833 & $11 / 91$ & $12 / 86$ & 0.712179 & $14 / 67$ & $6 / 81$ & 0.016888 \\
\hline $\begin{array}{l}\text { Koriyama et al. } \\
(2001)\end{array}$ & Brazil & $17 / 151(11.2 \%)$ & $15 / 102$ & $2 / 49$ & 0.05314 & $6 / 66$ & $11 / 84$ & 0.442513 & $3 / 11$ & $8 / 95$ & 0.052271 \\
\hline $\begin{array}{l}\text { Lopes et al. } \\
(2004)\end{array}$ & Brazil & $6 / 53(11.3 \%)$ & $5 / 30$ & $1 / 17$ & 0.287087 & $1 / 27$ & $5 / 18$ & 0.019945 & $1 / 6$ & $2 / 22$ & 0.594853 \\
\hline $\begin{array}{l}\text { Yoshiwara et al. } \\
(2005)\end{array}$ & Peru & $10 / 254(3.9 \%)$ & $5 / 115$ & $5 / 123$ & 1 & $4 / 127$ & $6 / 117$ & 1 & & & \\
\hline \multirow[t]{2}{*}{$\begin{array}{l}\text { Corvalán et al. } \\
(2001)\end{array}$} & Chile & $31 / 185(16.8 \%)$ & $23 / 121$ & $8 / 69$ & 0.183499 & $10 / 114$ & $21 / 71$ & $<0.001$ & $25 / 119$ & $4 / 63$ & 0.01015 \\
\hline & Consolidate & $153 / 1427(10.7 \%)$ & $119 / 830$ & $34 / 567$ & $<0.001$ & $40 / 613$ & $82 / 602$ & $<0.001$ & $59 / 395$ & $28 / 417$ & $<0.001$ \\
\hline
\end{tabular}

The meta-analytic estimated prevalence of EBV positivity in the region was $11.49 \%(95 \% \mathrm{CI}=8.46$ to 15.43$)$.

Meta-analyses was performed by a random-effects model with the Inverse variance method, using the DerSimonian-Laird estimator, an logit transformation and the ClopperPearson confidence interval for individual studies.

$\mathrm{I} 2=73.3 \%(p<0.001)$.

bind to host proteins and are generally used as a target for EBV detection by in situ hybridization (ISH) [21]. The EBNA-1 and -2 genes are exclusively nuclear proteins expressed in latent infected gastric carcinoma cells, and related with the disruption of promyelocytic leukemia nuclear bodies [22]. EBNA-1 is a DNA binding protein that lacks enzymatic activity, although is able to bind with some cellular proteins, such as CK2 and possibly P32/TAP [23]. In addition, an important partner of EBNA-1 is the ubiquitin-specific protease USP7, which is able to stabilize p53 and mdm2 [24]. Interestingly EBNA-1 is expressed in all of the EBV-associated tumors and is involved in viral DNA replication, mitotic segregation and transcriptional activation [25]. BART genes are highly expressed and multispliced RNAs whose protein-coding function is highly controversial [26]. Although some BARTs open reading frames (ORFs) have been predicted, it remains unclear whether any of them can be endogenously translated. In addition, BART small and long non-coding RNAs are highly expressed and associated with oncogenic

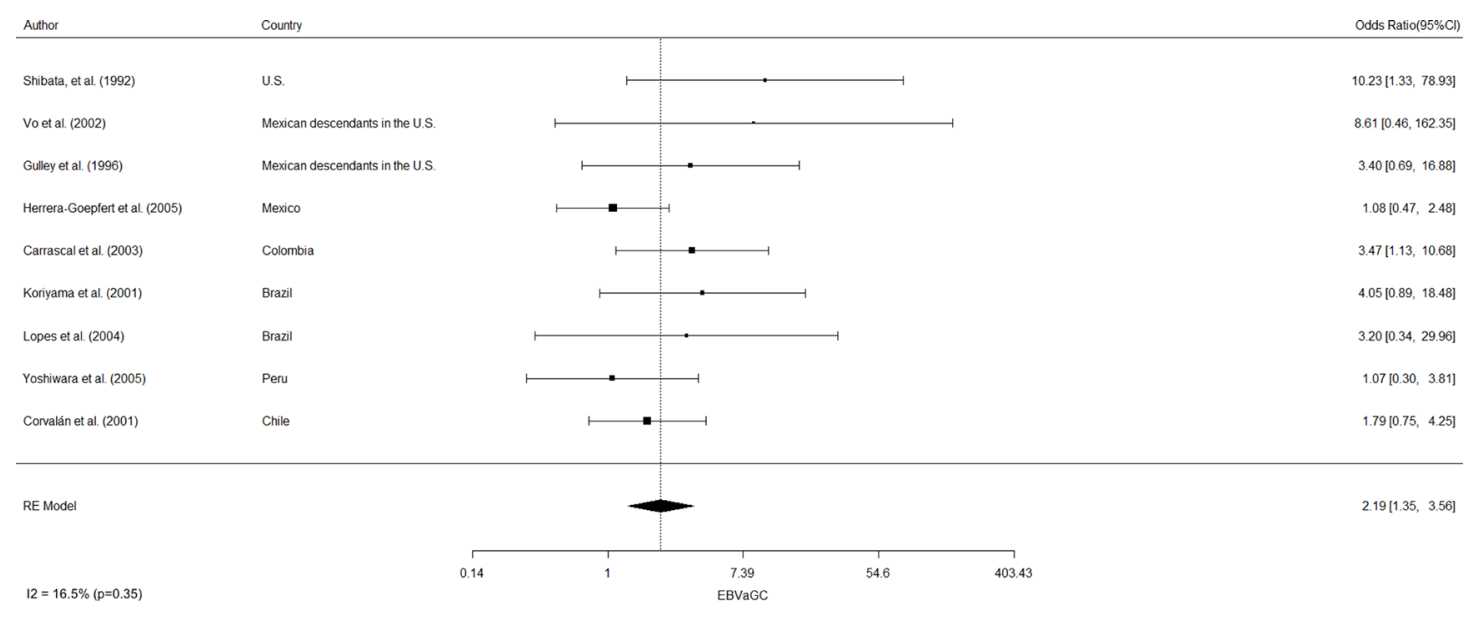

Figure 1: Estimated odds ratio (95\% CI) for male predominance of EBV-associated gastric cancer in the Americas. Meta-analyses were performed by a random-effects model with the Inverse variance method, using the DerSimonian-Laird estimator, a logit transformation and the Clopper-Pearson confidence interval for individual studies. The results are shown in a log-scale. 
transformation and immune evasion functions [27, 28] (for review see $[17,20])$. The LMP-1 and -2 genes encode for transmembrane proteins, with a plethora of oncogenic functions with conflicting results in gastric carcinoma $[29,30]$. Interestingly, variations in its sequences might be associated with phylogeographic diversity of EBV strains in EBVaGC throughout the world [31, 32]. Taken together, EBV latent genes not only define the type of latency, but are associated with oncogenic transformation, immune evasion, and the genetic diversity of EBVaGC.

\section{EBV strains and EBV-associated gastric carcinoma}

Previous characterization of restriction fragment length polymorphisms (RFLP) and the recently completed genome sequencing of 31 viruses lead towards the first global assessment of the genetic diversity of EBV. Twentyfive of these sequences were obtained from viruses present in malignant tumors, including 9 EBVaGC [33] and 7 cases which were isolated from benign lesions or healthy individuals [34-37]. Based on these data, five specific types (A, B, C, D and F) of EBV have been identified. Types $\mathrm{A}$ and $\mathrm{B}$ are defined by the substitution of $1.8 \mathrm{~kb}$ in the C-terminal domain of the EBNA-2 gene [38]. Subtype A is the predominant strain in Western and Asian countries, whereas subtype B is frequently found in Africa $[38,39]$. In addition, these two types of EBV differ in their capacity to transform B-lymphocytes to a proliferative state [40]. RFLPs at the BamHI W1/I1 boundary region identify subtypes $\mathrm{C}$ and D. Type $\mathrm{C}$ lacks the BamHI site and is more frequent in Asia among healthy individuals and EBV-associated diseases [41-44]. Conversely, subtype $\mathrm{D}$ (which has retained the BamHI restriction site) prevails in Western countries [41, 45]. Another polymorphism at the BamHI site defines the F type, of which the prototype BamHI F virus is found worldwide, but the " $\mathrm{f}$ " variant, characterized by the presence of an extra BamHI site, is found only in cases of nasopharyngeal carcinomas (NPC) from Southern China [46]. Finally, two more variants of EBV have been described associated with the LMP1 gene. A polymorphism of the Xho I restriction site at exon 1 of the LMP-1 gene (position 169425), defines western and Asian strains. The lack Xho I restriction site is common in healthy individuals and EBV-associated diseases in Asia [41], while the presence of the Xho I site is frequently observed in Western countries [47]. In addition, a C-terminal 30-base pair deletion (position 168287-168256) of the LMP-1 gene has been described [48]. However, this variant has not been associated with any specific geographical areas.

\section{Relevance of EBV strain variations in EBV- associated gastric carcinoma in the Americas}

Corvalan and coworkers [31] found that both polymorphisms at the BamHI $\mathrm{W} 1 / \mathrm{I} 1$ boundary region (subtypes C and D) and Xho I RFLPs at exon 1 of the LMP-1 gene were present in healthy donors. These authors also identified 2 unique novel recombinant strains, the type C/kept Xho I site and type D/lack of Xho I site [31]. These findings reflect the admixture of different ethnic populations in the Americas [49, 50]. Interestingly, in the case of EBVaGCs, tumors harbor only the western genotype (subtype D and kept Xho I site) $(p<0.001)$. Accordingly, cosegregation of these polymorphisms in EBVaGC was highly significant (OR 16.3 [95\% CI 2.5-685]). A consolidated overview of EBV strains in healthy donors and EBVaGC in the Americas is shown in Table 2. Taken together, these findings suggest that EBVaGC in the Americas might be almost exclusively associated to strains from western countries, despite the presence of recombinant strains among healthy donors. Similar findings have been described for H.pylori and gastric carcinoma, human papillomavirus and cervical cancer and M. tuberculosis and tuberculosis (for a review

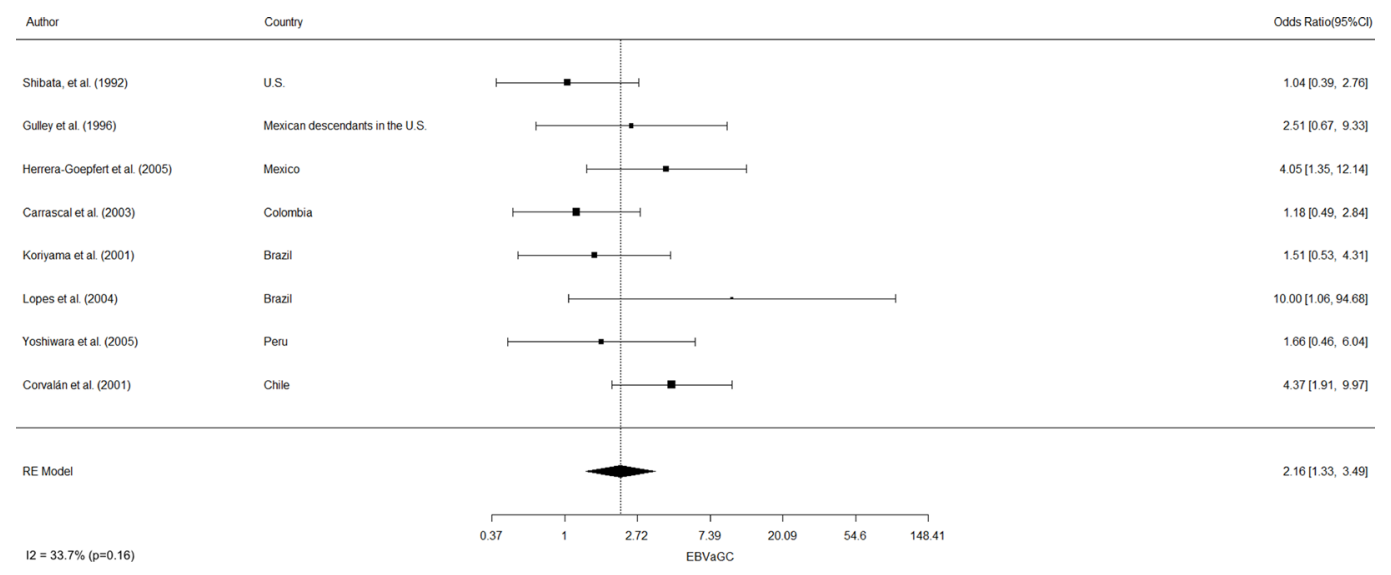

Figure 2: Estimated odds ratio (95\% CI) for diffuse-type histology of EBV-associated gastric carcinoma in the Americas. Meta-analyses were performed by a random-effects model with the Inverse variance method, using the DerSimonian-Laird estimator, a logit transformation and the Clopper-Pearson confidence interval for individual studies. The results are shown in a log-scale. 
Table 2: EBV strains in healthy donors (HD) and EBV-associated gastric carcinoma in the Americas

\begin{tabular}{|c|c|c|c|c|c|c|c|c|c|c|c|c|c|c|c|c|c|c|c|c|c|}
\hline \multirow[b]{3}{*}{ References } & \multirow[b]{3}{*}{ Country } & \multicolumn{5}{|c|}{ EBNA } & \multicolumn{5}{|c|}{ F/f variant } & \multicolumn{5}{|c|}{ type $\mathrm{C} / \mathrm{D}$} & \multicolumn{5}{|c|}{ XhoI kept/loss } \\
\hline & & \multicolumn{2}{|l|}{ A } & \multicolumn{3}{|c|}{ B } & \multicolumn{2}{|l|}{$F$} & \multicolumn{3}{|c|}{$\mathrm{f}$} & \multicolumn{2}{|l|}{ C } & \multicolumn{3}{|c|}{ D } & \multicolumn{2}{|c|}{ kept } & \multicolumn{3}{|c|}{ loss } \\
\hline & & EBVaGC & HD & EBVaGC & HD & $p$ value & EBVaGC & HD & EBVaGC & HD & $p$ value & EBVaGC & HD & EBVaGC & HD & $p$ value & EBVaGC & HD & EBVaGC & HD & $p$ value \\
\hline $\begin{array}{l}\text { Herrera- } \\
\text { Goepfert et al. } \\
\text { (2005) }\end{array}$ & Mexico & 5 & ND & 0 & $\mathrm{ND}$ & $\mathrm{ND}$ & 5 & $\mathrm{ND}$ & 0 & $\mathrm{ND}$ & ND & 5 & $\mathrm{ND}$ & 0 & ND & ND & 1 & ND & 4 & ND & ND \\
\hline $\begin{array}{l}\text { Corvalán et al. } \\
\text { (2006) }\end{array}$ & Colombia & 23 & 159 & 6 & 15 & 0.048176 & 29 & 100 & 0 & 8 & 0.046186 & 2 & 40 & 27 & 116 & 0.026917 & 25 & 115 & 4 & 55 & 0.043103 \\
\hline $\begin{array}{l}\text { Ordonez et al. } \\
\text { (2011) }\end{array}$ & Peru & 0 & ND & ND & ND & ND & ND & ND & ND & ND & ND & 5 & 101 & 6 & 17 & 0.00088 & 9 & 17 & 2 & 105 & 0 \\
\hline \multirow[t]{2}{*}{$\begin{array}{l}\text { Corvalán et al. } \\
\text { (2006) }\end{array}$} & Chile & 36 & 98 & 5 & 7 & 0.27439 & 40 & 94 & 0 & 9 & 0.012438 & 0 & 45 & 35 & 54 & 0 & 35 & 19 & 0 & 45 & 0 \\
\hline & Consolidate & 64 & 257 & 11 & 22 & 0.072 & 74 & 194 & 0 & 17 & $<0.001$ & 12 & 186 & 68 & 187 & $<0.001$ & 70 & 151 & 10 & 160 & $<0.001$ \\
\hline
\end{tabular}

see [51]. In the case of H.pylori and gastric carcinoma, de Sablet et al. [52] identified that strains from the high-risk region were all of European origin, whereas those from the low-risk region were of either European (34\%) or African origin (66\%). Similar findings have been described for M. tuberculosis and human papillomavirus [51] and the concept of "disrupted co-evolution" between the pathogen and its host has been proposed as a contributor for the phylogeographic origin of disease. Here, we propose that this might be the case for EBVaGC, where both Western and Asian wild-type strains and recombinant strains are present in healthy donors. However, only the western wild-type strain is present in gastric cancer. The natural variation of EBV should be further inquired by sequencing a large number of EBV-positive gastric cancer cases and healthy donors.

\section{Role of host molecular signaling in the pathogenesis of EBV-associated gastric carcinoma}

The TCGA network has proposed a novel molecular classification of gastric carcinoma that recognizes, for the first time, a subtype of tumors positive for Epstein-Barr virus: the EBVaGC. This subtype often displays frequent $P I K 3 C A$ mutations, amplification of $J A K 2$, CD274 (also known as PD-L1) and PDCD1LG2 (also known as PDL2), as well as unique $\mathrm{CpG}$ island methylator phenotype (CIMP) [4]. Although overexpression of PIK3CA has not been significantly associated with any clinicopathological features, loss of PTEN, a negative regulator of PIK3CA, was independently associated with poor prognosis ( $p=0.011)$ [53]. It has been proposed that the PI3K/AKT signaling pathway might also contribute to the switch from latency to the lytic state of the virus, a process known as EBV reactivation [54, 55]. Iwakiri and Takada [56] have shown that PI3K/AKT signal transduction contributes to the transcription of the BZLF1 gene, the master regulator of the lytic cycle and one of the most important genes in the reactivation of the EBV $[54,55]$. The main EBV oncoproteins LMP-1 and -2 can activate the PI3K/AKT pathway through the CTAR regions of their transmembrane domains, activating downstream signaling pathways [57]. Polymorphisms of Xho I site at exon 1 of the LMP-1 gene [31] might influence this activation favoring global differences of EBVaGC. Further experiments to confirm this issue are warranted. The JAK STAT pathway is involved in a range of physiological and cellular processes. $J A K 2$ gene is amplified and overexpressed in $\mathrm{EBVaGCs}$, but no significant association with survival was found [58]. Administration of JAK2 inhibitors, such as AZD1480, AG-490 and WP-1066, may represent potential therapeutic strategies for EBVaGC [59-61]. Significant amplification of PD-L1 was found in EBVaGC [62]. However, this finding was not associated with any clinicopathological characteristics or survival rates [58]. Interestingly, LMP-1 cooperates with IFNgamma to increase the expression of PD-L1 and this overexpression is suppressed by knocking down LMP-1 in EBV positive cell lines [63]. One final characteristic of the EBVaGC by the TCGA is the highest frequency of DNA hypermethylation [19]. Evaluation of promoter and nonpromoter $\mathrm{CpG}$ islands of the human genome has found that EBV infection leads to an extensive methylation of both host and viral genomes, being more extensive than any tumor type from the TCGA network [4, 64, 65]. In particular, hypermethylation of the CDKN2A promoter region has been detected in all studies [10, 19, 66-71]. Whether specific patterns of DNA hypermethylation may be associated to EBVaGC in the Americas is another question which remains to be answered.

\section{Role of environmental conditions in the pathogenesis of EBV-associated gastric carcinoma}

\section{Birth order and age}

In America, Campos et al. [72] reported that patients born as the eldest child showed the lowest frequency of EBVaGCs $(\mathrm{OR}=0.2,95 \% \mathrm{CI}=0.1-0.8, P=0.007)$. These findings were contrary to what has been reported in Asia, where EBVaGC was more frequently observed among eldest child [73]. In America, children got the first EBV infection at a younger age than in eastern populations [74]. This can be an important issue which should be further investigated. A relationship between EBVaGC and onset age for EBV infection has been reported in Mexican-descendants in the U.S, as well as residents from Mexico and Brazil $[9,11,14]$. A proportion of EBVaGC at younger age has also been reported in Colombia and Chile $[12,16]$. Further research is required to clarify the relevance of this issue. 


\section{Tobacco and alcohol consumption}

In Colombia, Mexico and Honduras, smoking has been associated to the onset of EBVaGC (48\%, 43\% and $46 \%$, respectively) [11, 75-77]. The association between alcohol consumption and the risk of EBVaGC has been explored in Honduras [76, 77], presenting 43\% of association. The relationship between smoking, EBV infection and the risk of developing gastric cancer should be an interesting topic for future investigation. An international case-case comparison of smoking and alcohol consumption associated with EBVaGC risk, including the aforementioned studies [77], indicate that smoking association is stronger for EBV-positive tumors (OR $=1.5$ [95\% CI 1.01-2.3]). In the case of alcohol consumption, a null association was found [77]. Further research in the Americas will be necessary to better determine these associations.

\section{Diet}

A study conducted in Cali, Colombia reported no associations between EBVaGC and high salt intake or exposure to metallic dust [75]. In addition, no significant associations were found with other dietary habits including salt, fruit and vegetable intake; steamed, fried or smoked foods; or food preparations by baking (oven), barbequing (coal) or roasting [75]. These results are unique to the Americas and contrary to those reported in Asia, where EBVaGC has been associated to metallic dust exposure and salt intake [73]. On the other hand, a study in Korean population reported that daily intake of the mycotoxin aflatoxin B1 (AFB1) was significantly higher among gastric cancer patients when compared with control subjects $(1.65 \pm 0.72$ and $1.91 \pm 0.87 \mathrm{ng} /$ $\mathrm{Kg}$ /day, respectively, $p<0.0001$ ) [78]. In addition, Accardi et al. [79] demonstrated that AFB1 stimulates EBV-mediated B-cell transformation using some in vitro and in vivo approaches, suggesting that this mycotoxin is a co-factor in EBV-mediated carcinogenesis [79]. Thus, the possibility that AFB1 works as a cofactor in EBVaGC in the Americas warrants additional epidemiological and laboratory research.

\section{H.pylori infection}

Infection with H.pylori is strongly associated with the progression of the gastric precancerous cascade and the development of intestinal type gastric cancer $[80,81]$. Camargo and coworkers [82] have recently compared H.pylori serologic profiles of EBV-positive and EBVnegative gastric cancer patients from five countries, including 2 from the Americas (Mexico and Honduras). These authors found a marginal statistical significance of catalase antibodies in the EBVaGC group $(\mathrm{OR}=3.15$ $[95 \% \mathrm{CI}=1.50-6.61])$ with no regional differences.

\section{EBVaGC and lymphoepithelioma-like carcinoma of the stomach}

Watanabe and coworkers [83] described "gastric carcinoma with lymphoid stroma" as a group of tumors showing microalveolar, trabecular, or primitive-tubular patterns with uniformly dense and diffuse lymphoid cell infiltration (Figure 3). This unique phenotype was later

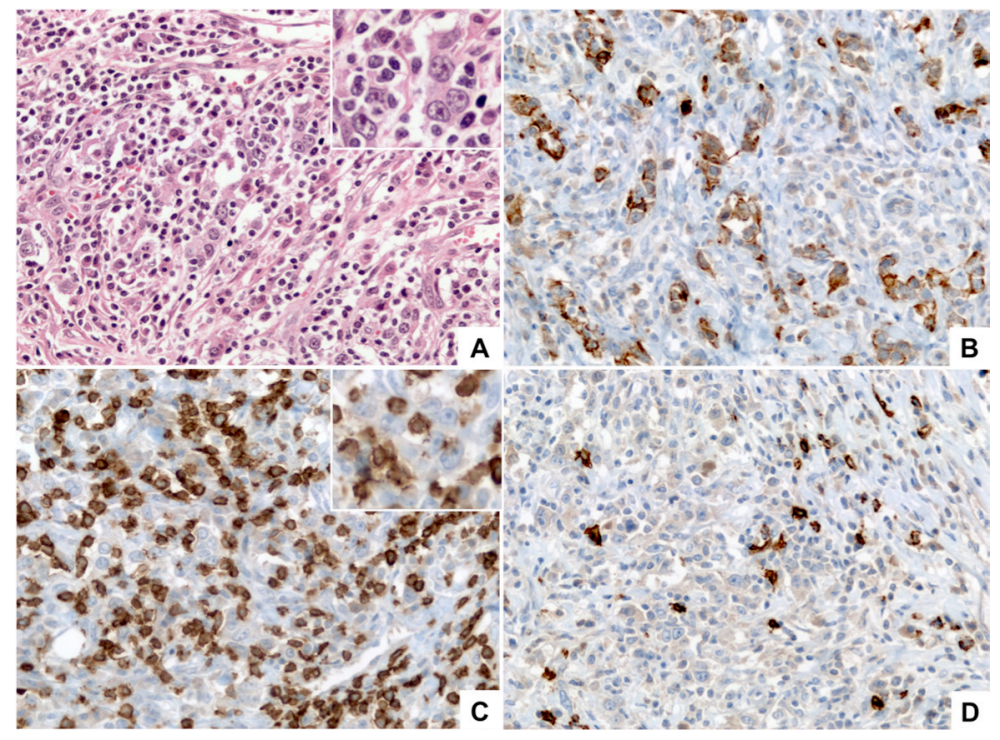

Figure 3: Lymphoepithelioma-like (LEL) carcinoma. (A) (HE, 400×) shows a poorly differentiated carcinoma formed by medium to large size tumor cells with vesicular nuclei, prominent nucleoli and small amount of eosinophilic cytoplasm (inset) arranged in small clusters and poorly formed cords, intermingled with numerous lymphocytes. (B) (Pan-Cytokeratin AE1/AE3, 400×) shows that the tumor cells are positive for cytokeratins demonstrating their epithelial nature and highlighting the poorly formed clusters and cords arrangement. (C) $(C D 3,400 \times)$ highlights the diffuse lymphocytic infiltrate composed mainly by mature T lymphocytes; tumor cells are negative for CD3 (inset). (D) (CD20, 400×) highlights scattered B-lymphocytes within the infiltrate. 
defined as lymphoepithelioma-like (LEL) carcinoma and associated with EBV by 3 independent groups [84-86], although it was also recently described as a feature of the MSI subtype of GC [87]. Tumor cells of LEL are immunohistochemically positive for AE3-defined keratin, confirming their epithelial nature. Therefore, the diffuse lymphoid infiltration is a mixture of CD3-positive $\mathrm{T}$ cells and CD20-positive B cells (Figure 3). The presence of EBV has been demonstrated in $80 \%-86 \%$ of cases $[88,89]$. Retrospective evaluation of a 274-case series from a 14-year period (ordinary gastric carcinoma cases matched by age and sex) showed that LEL tumors had distinct clinicopathologic features and more favorable prognosis [88]. Interestingly, almost half of LEL EBVpositive cases with differentiated components showed the presence of EBV in the non-LEL component as well [88]. Gutierrez and colleagues [90] classified EBV into five subtypes, based on the EBNA-1 sequence in the carboxy-terminal region, which we have named according to the amino acid at position 487 in EBNA-1. Since this amino acid residue was highly predictive of the observed mutation patterns, they termed two of these subtypes as 'prototypes' (P-ala and P-thr). On the other hand, they identified 3 other subtypes as "variants" (V-pro, V-leu and $\mathrm{V}$-val), because they differed more markedly from P-ala than does P-thr. According to this EBV classification, Cheng and coworkers [89] compared clinical and molecular features of LEL EBV-positive with EBVaGC and demonstrated that the V-leu and P-ala subtypes were predominant in EBV-positive gastric LEL, which is different from the predominant V-val subtype in ordinary EBVaGC. In addition, EBV-positive gastric LELC has a favorable prognosis when compared to ordinary EBVaGC (median survival time 43.0 vs. 18.0 months, $p=0.035$ ). In the Americas, LEL carcinomas have been included as part of an EBVaGC series with prevalences ranging from $1.1 \%$ in Chile to $7.6 \%$ in Brazil $[13,16]$. Whether LEL is a variant of EBVaGC needs to be addressed in future investigations.

\section{CONCLUSIONS}

Novel molecular classifications and meta-analysis have identified EBV as a distinct etiological agent for gastric cancer. An important characteristic of EBVaGC is its higher prevalence in the Americas as compared to Asia. Our meta-analysis estimate a prevalence of $11.4 \%$ of EBV infection, more frequently observed in males with predominantly diffuse-type histology. Specific EBV genes such as EBERs, EBNAs, BARTs and LMP are the most actively expressed transcripts. Variations in the sequences of these genes might be associated with the observed phylogeographic diversity of EBV strains across the region. Polymorphisms at the BamHI W1/I1 boundary region and Xho I RFLPs at exon 1 of the LMP-1 gene have been found in healthy donors, reflecting the admixture of different ethnic populations in the Americas. However, this is not the case for gastric cancer, since almost all EBVaGCs harbor exclusively the western genotype (subtype D and kept Xho I site). We propose that "disrupted co-evolution" between EBV and healthy population might contribute to the origin of the disease. Patients born as the eldest child and age of onset of EBV infection are important issues that should be further investigated. Smoking is strong risk factor for EBV-positive tumors, but no associations have been found with dietary habits in the Americas. H.pylori infection identified a marginal statistical significance of catalase antibodies in the EBVaGC group. Finally, "gastric carcinomas with lymphoid stroma" described by Watanabe [83] is a common phenotype of MSI and EBV subtypes of GC [87]. LEL has been associated with EBV infection in more than $80 \%$ of cases, where most of LEL carcinomas have been included as part of EBVaGC series. Whether LEL is a variant of EBVaGC needs to be addressed in future investigations.

\section{Search strategy and selection criteria}

Data for this Review were identified by searches of PubMed/Scopus/Scielo from relevant articles published between 1959 and September 2016 in English, using the search terms "gastric cancer" and "Epstein-Barr virus" with special emphasis on articles published from the Americas (North, Central and South American countries). Epidemiological data were further searched by GLOBOCAN 2012 [91]. Only studies in which EBV was detected in primary tumors by in situ hybridization of EBER were considered. The resulting studies were manually curated according to their relevance to EBVaGC in the Americas and potentially relevant articles were then evaluated in detail. Meta-analyses summarizing frequencies of EBV by EBER in tumor gastric tissues from the Americas including information on the first author, year of publication, tumor location, size of study population and age and sex of the patients (Table 1). Due to the small number of studies available, clinical data were restricted to the variables mentioned above. Meta-analyses were performed by a random-effects model with the Inverse variance method, using the DerSimonian-Laird estimator, a logit transformation, and the Clopper-Pearson confidence interval for individual studies. The results are shown in a log-scale. The I2 statistic, which measures the extent of inconsistency between studies, was assessed. The 95\% confidence interval of the odds ratio was used to evaluate differences between groups. Meta-analyses methods are presented in the footnotes of figures and tables.

\section{DISCLAIMER}

The funders had no role in study design, data collection and analysis, decision to publish, or preparation of the paper. 


\section{Authors' contributions}

Gonzalo Carrasco: Conception or design of the work, Data collection, Data analysis and interpretation, Drafting the article, Critical revision of the article, Final approval of the version to be published.

Ismael Riquelme: Data collection, Drafting the article, Critical revision of the article, Final approval of the version to be published

Oslando Padilla: Data analysis and interpretation, Critical revision of the article, Final approval of the version to be published.

Miguel Villaseca: Data collection, Drafting the article, Critical revision of the article, Final approval of the version to be published.

Francisco R. Aguayo: Drafting the article, Critical revision of the article, Final approval of the version to be published.

Alejandro H. Corvalan: Conception or design of the work, Data collection, Data analysis and interpretation, Drafting the article, Critical revision of the article, Final approval of the version to be published.

\section{ACKNOWLEDGMENTS}

CONICYT-FONDAP 15130011, Fondecyt 1151411 and Fondecyt 1161219 from the Government of Chile.

\section{CONFLICTS OF INTEREST}

The authors declare that there is no conflicts of interests regarding the publication of this paper.

\section{REFERENCES}

1. Ferlay J, Soerjomataram I, Dikshit R, Eser S, Mathers C, Rebelo M, Parkin DM, Forman D, Bray F. Cancer incidence and mortality worldwide: sources, methods and major patterns in GLOBOCAN 2012. Int J Cancer. 2015; 136:E359-86. doi: 10.1002/ijc.29210.

2. Chatenoud L, Bertuccio P, Bosetti C, Malvezzi M, Levi F, Negri E, La Vecchia C. Trends in mortality from major cancers in the Americas: 1980-2010. Ann Oncol. 2014; 25:1843-53. doi: 10.1093/annonc/mdu206.

3. Mathers CD, Loncar D. Projections of global mortality and burden of disease from 2002 to 2030. PLoS Med. 2006; 3:e442. doi: 10.1371/journal.pmed.0030442.

4. Bass AJ. Comprehensive molecular characterization of gastric adenocarcinoma. Nature. 2014; 513:202-9. doi:10.1038/nature13480.

5. Lee JH, Kim SH, Han SH, An JS, Lee ES, Kim YS. Clinicopathological and molecular characteristics of Epstein-Barr virus-associated gastric carcinoma: a metaanalysis. J Gastroenterol Hepatol. 2009; 24:354-65. doi: 10.1111/j.1440-1746.2009.05775.x.
6. Murphy G, Pfeiffer R, Camargo MC, Rabkin CS. Metaanalysis shows that prevalence of Epstein-Barr viruspositive gastric cancer differs based on sex and anatomic location. Gastroenterology. 2009; 137:824-33. doi: 10.1053/j.gastro.2009.05.001.

7. Camargo MC, Murphy G, Koriyama C, Pfeiffer RM, Kim WH, Herrera-Goepfert R, Corvalán AH, Carrascal E, Abdirad A, Anwar M, Hao Z, Kattoor J, YoshiwaraWakabayashi E, et al. Determinants of Epstein-Barr viruspositive gastric cancer: an international pooled analysis. $\mathrm{Br}$ J Cancer. 2011; 105:38-43. doi: 10.1038/bjc.2011.215.

8. Shibata D, Weiss LM. Epstein-Barr virus-associated gastric adenocarcinoma. Am J Pathol. 1992; 140:769-74.

9. Gulley ML, Pulitzer DR, Eagan PA, Schneider BG. Epstein-Barr virus infection is an early event in gastric carcinogenesis and is independent of bcl-2 expression and p53 accumulation. Hum Pathol. 1996; 27:20-7.

10. Vo QN, Geradts J, Gulley ML, Boudreau DA, Bravo JC, Schneider BG. Epstein-Barr virus in gastric adenocarcinomas: association with ethnicity and CDKN2A promoter methylation. J Clin Pathol. 2002; 55:669-75.

11. Herrera-Goepfert R, Akiba S, Koriyama C, Ding S, Reyes E, Itoh T, Minakami Y, Eizuru Y. Epstein-Barr virus-associated gastric carcinoma: Evidence of age-dependence among a Mexican population. World J Gastroenterol. 2005; 11:6096-103.

12. Carrascal E, Koriyama C, Akiba S, Tamayo O, Itoh T, Eizuru Y, Garcia F, Sera M, Carrasquilla G, Piazuelo MB, Florez L, Bravo JC. Epstein-Barr virus-associated gastric carcinoma in Cali, Colombia. Oncol Rep. 2003; 10:1059-62.

13. Koriyama C, Akiba S, Iriya K, Yamaguti T, Hamada GS, Itoh T, Eizuru Y, Aikou T, Watanabe S, Tsugane S, Tokunaga M. Epstein-Barr virus-associated gastric carcinoma in Japanese Brazilians and non-Japanese Brazilians in Sao Paulo. Jpn J Cancer Res. 2001; 92:911-7.

14. Lopes LF, Bacchi MM, Elgui-de-Oliveira D, Zanati SG, Alvarenga M, Bacchi CE. Epstein-Barr virus infection and gastric carcinoma in Sao Paulo State, Brazil. Braz J Med Biol Res. 2004; 37:1707-12.

15. Yoshiwara E, Koriyama C, Akiba S, Itoh T, Minakami Y, Chirinos JL, Watanabe J, Takano J, Miyagui J, Hidalgo H, Chacon P, Linares V, Eizuru Y. Epstein-Barr virusassociated gastric carcinoma in Lima, Peru. J Exp Clin Cancer Res. 2005; 24:49-54.

16. Corvalán AH, Koriyama C, Akiba S, Eizuru Y, Backhouse C, Palma M, Argandona J, Tokunaga M. Epstein-Barr virus in gastric carcinoma is associated with location in the cardia and with a diffuse histology: a study in one area of Chile. Int J Cancer. 2001; 94:527-30. doi: 10.1002/ijc.1510.

17. Tsao SW, Tsang CM, To KF, Lo KW. The role of EpsteinBarr virus in epithelial malignancies. J Pathol. 2015; 235:323-33. doi: 10.1002/path.4448.

18. Lieberman PM. Chromatin Structure of Epstein-Barr Virus Latent Episomes. Curr Top Microbiol Immunol. 2015; 390:71-102. doi: 10.1007/978-3-319-22822-8 5. 
19. Gulley ML. Genomic assays for Epstein-Barr virus-positive gastric adenocarcinoma. Exp Mol Med. 2015; 47:e134. doi: 10.1038/emm.2014.93.

20. Shinozaki-Ushiku A, Kunita A, Fukayama M. Update on Epstein-Barr virus and gastric cancer (review). Int J Oncol. 2015; 46:1421-34. doi: 10.3892/ijo.2015.2856.

21. Weiss LM, Chen YY. EBER in situ hybridization for Epstein-Barr virus. Methods Mol Biol. 2013; 999:223-30. doi: 10.1007/978-1-62703-357-2_16.

22. Sivachandran N, Wang X, Frappier L. Functions of the Epstein-Barr virus EBNA1 protein in viral reactivation and lytic infection. J Virol. 2012; 86:6146-58. doi: 10.1128/ JVI.00013-12.

23. Malik-Soni N, Frappier L. Proteomic profiling of EBNA1host protein interactions in latent and lytic Epstein-Barr virus infections. J Virol. 2012; 86:6999-7002. doi: 10.1128/ jvi.00194-12.

24. Frappier L, Verrijzer CP. Gene expression control by protein deubiquitinases. Curr Opin Genet Dev. 2011; 21:207-13. doi: 10.1016/j.gde.2011.02.005.

25. Frappier L. EBNA1. Curr Top Microbiol Immunol. 2015; 391:3-34. doi: 10.1007/978-3-319-22834-1_1.

26. Skalsky RL, Cullen BR. EBV Noncoding RNAs. Curr Top Microbiol Immunol. 2015; 391:181-217. doi: 10.1007/9783-319-22834-1_6.

27. Marquitz AR, Mathur A, Nam CS, Raab-Traub N. The Epstein-Barr Virus BART microRNAs target the proapoptotic protein Bim. Virology. 2011; 412:392-400. doi: 10.1016/j.virol.2011.01.028.

28. Marquitz AR, Mathur A, Edwards RH, Raab-Traub N. Host Gene Expression Is Regulated by Two Types of Noncoding RNAs Transcribed from the Epstein-Barr Virus BamHI A Rightward Transcript Region. J Virol. 2015; 89:11256-68. doi:10.1128/JVI.01492-15.

29. Luo B, Wang Y, Wang XF, Liang H, Yan LP, Huang BH, Zhao P. Expression of Epstein-Barr virus genes in EBVassociated gastric carcinomas. World J Gastroenterol. 2005; 11:629-33.

30. Accardi R, Fathallah I, Gruffat H, Mariggio G, Le CalvezKelm F, Voegele C, Bartosch B, Hernandez-Vargas H, McKay J, Sylla BS, Manet E, Tommasino M. Epstein Barr virus transforming protein LMP-1 alters B cells gene expression by promoting accumulation of the oncoprotein DeltaNp73alpha. PLoS Pathog. 2013; 9:e1003186. doi: 10.1371/journal.ppat.1003186.

31. Corvalán AH, Ding S, Koriyama C, Carrascal E, Carrasquilla G, Backhouse C, Urzua L, Argandona J, Palma M, Eizuru Y, Akiba S. Association of a distinctive strain of Epstein-Barr virus with gastric cancer. Int J Cancer. 2006; 118:1736-42. doi: 10.1002/ijc.21530.

32. Chen JN, Ding YG, Feng ZY, Li HG, He D, Du H, Wu $\mathrm{B}$, Shao CK. Association of distinctive Epstein-Barr virus variants with gastric carcinoma in Guangzhou, southern China. J Med Virol. 2010; 82:658-67. doi: 10.1002/ jmv.21731.
33. Liu Y, Yang W, Pan Y, Ji J, Lu Z, Ke Y. Genome-wide analysis of Epstein-Barr virus (EBV) isolated from EBVassociated gastric carcinoma (EBVaGC). Oncotarget. 2015; 7:4903-14. doi: 10.18632/oncotarget.6751.

34. Baer R, Bankier AT, Biggin MD, Deininger PL, Farrell PJ, Gibson TJ, Hatfull G, Hudson GS, Satchwell SC, Seguin C, Tuffnell PS, Barrell BG. DNA sequence and expression of the B95-8 Epstein-Barr virus genome. Nature. 1984; 310:207-11.

35. de Jesus O, Smith PR, Spender LC, Elgueta Karstegl C, Niller HH, Huang D, Farrell PJ. Updated Epstein-Barr virus (EBV) DNA sequence and analysis of a promoter for the BART (CST, BARF0) RNAs of EBV. J Gen Virol. 2003; 84:1443-50. doi: 10.1099/vir.0.19054-0.

36. Lei Z, Tan IB, Das K, Deng N, Zouridis H, Pattison S, Chua C, Feng Z, Guan YK, Ooi CH, Ivanova T, Zhang S, Lee $\mathrm{M}$, et al. Identification of molecular subtypes of gastric cancer with different responses to PI3-kinase inhibitors and 5-fluorouracil. Gastroenterology. 2013; 145:554-65. doi: 10.1053/j.gastro.2013.05.010.

37. Santpere G, Darre F, Blanco S, Alcami A, Villoslada P, Mar Alba M, Navarro A. Genome-wide analysis of wildtype Epstein-Barr virus genomes derived from healthy individuals of the 1,000 Genomes Project. Genome Biol Evol. 2014; 6:846-60. doi: 10.1093/gbe/evu054.

38. Zimber U, Adldinger HK, Lenoir GM, Vuillaume M, Knebel-Doeberitz MV, Laux G, Desgranges C, Wittmann P, Freese UK, Schneider U. Geographical prevalence of two types of Epstein-Barr virus. Virology. 1986; 154:56-66.

39. Young LS, Yao QY, Rooney CM, Sculley TB, Moss DJ, Rupani H, Laux G, Bornkamm GW, Rickinson AB. New type B isolates of Epstein-Barr virus from Burkitt's lymphoma and from normal individuals in endemic areas. $\mathrm{J}$ Gen Virol. 1987; 68:2853-62. doi: 10.1099/0022-1317-6811-2853.

40. Young LS, Murray PG. Epstein-Barr virus and oncogenesis: from latent genes to tumours. Oncogene. 2003; 22:5108-21. doi: 10.1038/sj.onc. 1206556.

41. Lung ML, Chang RS, Jones JH. Genetic polymorphism of natural Epstein-Barr virus isolates from infectious mononucleosis patients and healthy carriers. J Virol. 1988; 62:3862-6.

42. Lung ML, Chang GC. Detection of distinct Epstein-Barr virus genotypes in NPC biopsies from southern Chinese and Caucasians. Int J Cancer. 1992; 52:34-7.

43. Sidagis J, Ueno K, Tokunaga M, Ohyama M, Eizuru Y. Molecular epidemiology of Epstein-Barr virus (EBV) in EBV-related malignancies. Int J Cancer. 1997; 72:72-6.

44. Lung ML, Chang RS, Huang ML, Guo HY, Choy D, Sham J, Tsao SY, Cheng P, Ng MH. Epstein-Barr virus genotypes associated with nasopharyngeal carcinoma in southern China. Virology. 1990; 177:44-53.

45. Abdel-Hamid M, Chen JJ, Constantine N, Massoud M, Raab-Traub N. EBV strain variation: geographical 
distribution and relation to disease state. Virology. 1992; 190:168-75.

46. Lung ML, Lam WP, Sham J, Choy D, Yong-Sheng Z, Guo $\mathrm{HY}, \mathrm{Ng} \mathrm{MH}$. Detection and prevalence of the " $\mathrm{f}$ " variant of Epstein-Barr virus in southern China. Virology. 1991; 185:67-71.

47. Khanim F, Yao QY, Niedobitek G, Sihota S, Rickinson AB, Young LS. Analysis of Epstein-Barr virus gene polymorphisms in normal donors and in virus-associated tumors from different geographic locations. Blood. 1996; 88:3491-501.

48. Wohlford EM, Asito AS, Chelimo K, Sumba PO, Baresel PC, Oot RA, Moormann AM, Rochford R. Identification of a novel variant of LMP-1 of EBV in patients with endemic Burkitt lymphoma in western Kenya. Infect Agent Cancer. 2013; 8:34. doi: 10.1186/1750-9378-8-34.

49. Halliburton IW. Intertypic recombinants of herpes simplex viruses. J Gen Virol. 1980; 48:1-23. doi: 10.1099/00221317-48-1-1.

50. Eyheramendy S, Martinez FI, Manevy F, Vial C, Repetto GM. Genetic structure characterization of Chileans reflects historical immigration patterns. Nat Commun. 2015; 6:6472. doi: $10.1038 /$ ncomms 7472 .

51. Kodaman N, Sobota RS, Mera R, Schneider BG, Williams SM. Disrupted human-pathogen co-evolution: a model for disease. Front Genet. 2014; 5.

52. de Sablet T, Piazuelo MB, Shaffer CL, Schneider BG, Asim M, Chaturvedi R, Bravo LE, Sicinschi LA, Delgado AG, Mera RM, Israel DA, Romero-Gallo J, Peek RM Jr, et al. Phylogeographic origin of Helicobacter pylori is a determinant of gastric cancer risk. Gut. 2011; 60:1189-95. doi: 10.1136/gut.2010.234468.

53. Kang HJ, Lee IS, Park YS, Ho WJ, Sohn D, Ahn JY, Yook JH, Kim BS. Biomarkers of EBV-positive Gastric Cancers: Loss of PTEN Expression is Associated with Poor Prognosis and Nodal Metastasis. Ann Surg Oncol. 2016; 23:3684-3692. doi: 10.1245/s10434-016-5284-2.

54. McKenzie J, El-Guindy A. Epstein-Barr Virus Lytic Cycle Reactivation. Curr Top Microbiol Immunol. 2015; 391:23761. doi: 10.1007/978-3-319-22834-1_8.

55. Li H, Liu S, Hu J, Luo X, Li N, M Bode A, Cao Y. EpsteinBarr virus lytic reactivation regulation and its pathogenic role in carcinogenesis. Int J Biol Sci. 2016; 12:1309-18. doi: 10.7150/ijbs. 16564 .

56. Iwakiri D, Takada K. Phosphatidylinositol 3-kinase is a determinant of responsiveness to $\mathrm{B}$ cell antigen receptormediated Epstein-Barr virus activation. J Immunol. 2004; 172:1561-6.

57. Chen J. Roles of the PI3K/Akt pathway in Epstein-Barr virus-induced cancers and therapeutic implications. World J Virol. 2012; 1:154-61. doi: 10.5501/wjv.v1.i6.154.

58. Dong M, Wang HY, Zhao XX, Chen JN, Zhang YW, Huang Y, Xue L, Li HG, Du H, Wu XY, Shao CK. Expression and prognostic roles of PIK3CA, JAK2, PD-L1 and PD-L2 in EBV-associated gastric carcinoma. Hum Pathol. 2016; 53:25-34. doi: 10.1016/j.humpath.2016.02.007.

59. Plimack ER, Lorusso PM, McCoon P, Tang W, Krebs AD, Curt G, Eckhardt SG. AZD1480: a phase I study of a novel JAK2 inhibitor in solid tumors. Oncologist. 2013; 18:81920. doi: 10.1634/theoncologist.2013-0198.

60. Qian C, Wang J, Yao J, Wang L, Xue M, Liu W, Si J. Involvement of nuclear JAK2 signaling in AG490-induced apoptosis of gastric cancer cells. Anat Rec (Hoboken). 2013; 296:1865-73. doi: 10.1002/ar.22820.

61. Judd LM, Menheniott TR, Ling H, Jackson CB, Howlett M, Kalantzis A, Priebe W, Giraud AS. Inhibition of the JAK2/ STAT3 pathway reduces gastric cancer growth in vitro and in vivo. PLoS One. 2014; 9:e95993. doi: 10.1371/journal. pone.0095993.

62. Boger C, Behrens HM, Mathiak M, Kruger S, Kalthoff H, Rocken C. PD-L1 is an independent prognostic predictor in gastric cancer of Western patients. Oncotarget. 2016; 7:24269-83. doi: 10.18632/oncotarget.8169.

63. Fang W, Zhang J, Hong S, Zhan J, Chen N, Qin T, Tang Y, Zhang Y, Kang S, Zhou T, Wu X, Liang W, Hu Z, et al. EBV-driven LMP1 and IFN-gamma up-regulate PD-L1 in nasopharyngeal carcinoma: Implications for oncotargeted therapy. Oncotarget. 2014; 5:12189-202. doi: 10.18632/ oncotarget.2608.

64. Zouridis H, Deng N, Ivanova T, Zhu Y, Wong B, Huang D, Wu YH, Wu Y, Tan IB, Liem N, Gopalakrishnan V, Luo Q, $\mathrm{Wu}$ J, et al. Methylation subtypes and large-scale epigenetic alterations in gastric cancer. Sci Transl Med. 2012; 4: 156ra40. doi: 10.1126/scitranslmed.3004504.

65. Loh M, Liem N, Vaithilingam A, Lim PL, Sapari NS, Elahi E, Mok ZY, Cheng CL, Yan B, Pang B, Salto-Tellez M, Yong WP, Iacopetta B, et al. DNA methylation subgroups and the $\mathrm{CpG}$ island methylator phenotype in gastric cancer: a comprehensive profiling approach. BMC Gastroenterol. 2014; 14:55. doi: 10.1186/1471-230X-14-55.

66. Ryan JL, Jones RJ, Kenney SC, Rivenbark AG, Tang W, Knight ER, Coleman WB, Gulley ML. Epstein-Barr virusspecific methylation of human genes in gastric cancer cells. Infect Agent Cancer. 2010; 5:27. doi: 10.1186/1750-93785-27.

67. Ferrasi AC, Pinheiro NA, Rabenhorst SH, Caballero OL, Rodrigues MA, de Carvalho F, Leite CV, Ferreira MV, Barros MA, Pardini MI. Helicobacter pylori and EBV in gastric carcinomas: methylation status and microsatellite instability. World J Gastroenterol. 2010; 16:312-9.

68. Bernal C, Vargas M, Ossandon F, Santibanez E, Urrutia J, Luengo V, Zavala LF, Backhouse C, Palma M, Argandona J, Aguayo F, Corvalán AH. DNA methylation profile in diffuse type gastric cancer: evidence for hypermethylation of the BRCA1 promoter region in early-onset gastric carcinogenesis. Biol Res. 2008; 41:303-15.

69. McCormick TM, Canedo NH, Furtado YL, Silveira FA, de Lima RJ, Rosman AD, Almeida Filho GL, Carvalho Mda 
G. Association between human papillomavirus and Epstein - Barr virus DNA and gene promoter methylation of RB1 and CDH1 in the cervical lesions: a transversal study. Diagn Pathol. 2015; 10:59. doi: 10.1186/s13000-015-0283-3.

70. He D, Zhang YW, Zhang NN, Zhou L, Chen JN, Jiang Y, Shao CK. Aberrant gene promoter methylation of p16, FHIT, CRBP1, WWOX, and DLC-1 in Epstein-Barr virusassociated gastric carcinomas. Med Oncol. 2015; 32:92. doi: 10.1007/s12032-015-0525-y.

71. Qu Y, Dang S, Hou P. Gene methylation in gastric cancer. Clin Chim Acta. 2013; 424:53-65. doi: 10.1016/j. cca.2013.05.002.

72. Campos FI, Koriyama C, Akiba S, Carrasquilla G, Serra M, Carrascal E, Itoh T, Minakami Y, Eizuru Y. Environmental factors related to gastric cancer associated with EpsteinBarr virus in Colombia. Asian Pac J Cancer Prev. 2006; 7:633-7.

73. Koriyama C, Akiba S, Minakami Y, Eizuru Y. Environmental factors related to Epstein-Barr virusassociated gastric cancer in Japan. J Exp Clin Cancer Res. 2005; 24:547-53.

74. Chabay PA, Preciado MV. EBV primary infection in childhood and its relation to B-cell lymphoma development: a mini-review from a developing region. Int J Cancer. 2013; 133:1286-92. doi: 10.1002/ijc.27858.

75. Campos FI, Koriyama C, Akiba S, Carrasquilla G, Serra M, Carrascal E, Yamamoto M, Nakano A. Toenail zinc level and gastric cancer risk in Cali, Colombia. J Cancer Res Clin Oncol. 2008; 134:169-78. doi: 10.1007/s00432-007-0266-1.

76. Ryan JL, Morgan DR, Dominguez RL, Thorne LB, Elmore SH, Mino-Kenudson M, Lauwers GY, Booker JK, Gulley ML. High levels of Epstein-Barr virus DNA in latently infected gastric adenocarcinoma. Lab Invest. 2009; 89:80 90. doi: 10.1038/labinvest.2008.103.

77. Camargo MC, Koriyama C, Matsuo K, Kim WH, HerreraGoepfert R, Liao LM, Yu J, Carrasquilla G, Sung JJ, Alvarado-Cabrero I, Lissowska J, Meneses-Gonzalez F, Yatabe Y, et al. Case-case comparison of smoking and alcohol risk associations with Epstein-Barr virus-positive gastric cancer. Int J Cancer. 2014; 134:948-53. doi: 10.1002/ijc.28402.

78. Eom SY, Yim DH, Zhang Y, Yun JK, Moon SI, Yun HY, Song YJ, Youn SJ, Hyun T, Park JS, Kim BS, Lee JY, Kim YD, et al. Dietary aflatoxin B1 intake, genetic polymorphisms of CYP1A2, CYP2E1, EPHX1, GSTM1, and GSTT1, and gastric cancer risk in Korean. Cancer Causes Control. 2013; 24:1963-72. doi: 10.1007/s10552013-0272-3.

79. Accardi R, Gruffat H, Sirand C, Fusil F, Gheit T, HernandezVargas H, Le Calvez-Kelm F, Traverse-Glehen A, Cosset FL, Manet E, Wild CP, Tommasino M. The mycotoxin aflatoxin B1 stimulates Epstein-Barr virus-induced B-cell transformation in in vitro and in vivo experimental models. Carcinogenesis. 2015; 36:1440-51. doi: 10.1093/carcin/bgv142.
80. Sandoval-Borquez A, Saavedra K, Carrasco-Avino G, Garcia-Bloj B, Fry J, Wichmann I, Corvalan AH. Noncoding Genomics in Gastric Cancer and the Gastric Precancerous Cascade: Pathogenesis and Biomarkers. Disease Markers. 2015; 2015:14. doi: 10.1155/2015/503762.

81. Valenzuela MA, Canales J, Corvalan AH, Quest AF. Helicobacter pylori-induced inflammation and epigenetic changes during gastric carcinogenesis. World $\mathrm{J}$ Gastroenterol. 2015; 21:12742-56. doi: 10.3748/wjg.v21. i45.12742.

82. Camargo MC, Kim KM, Matsuo K, Torres J, Liao LM, Morgan DR, Michel A, Waterboer T, Zabaleta J, Dominguez RL, Yatabe Y, Kim S, Rocha-Guevara ER, et al. AntiHelicobacter pylori Antibody Profiles in Epstein-Barr virus (EBV)-Positive and EBV-Negative Gastric Cancer. Helicobacter. 2015. doi: 10.1111/hel.12249.

83. Watanabe H, Enjoji M, Imai T. Gastric carcinoma with lymphoid stroma. Its morphologic characteristics and prognostic correlations. Cancer. 1976; 38:232-43.

84. Burke AP, Yen TS, Shekitka KM, Sobin LH. Lymphoepithelial carcinoma of the stomach with EpsteinBarr virus demonstrated by polymerase chain reaction. Mod Pathol. 1990; 3:377-80.

85. Weiss LM, Gaffey MJ, Shibata D. Lymphoepithelioma-like carcinoma and its relationship to Epstein-Barr virus. Am J Clin Pathol. 1991; 96:156-8.

86. Min KW, Holmquist S, Peiper SC, O'Leary TJ. Poorly differentiated adenocarcinoma with lymphoid stroma (lymphoepithelioma-like carcinomas) of the stomach. Report of three cases with Epstein-Barr virus genome demonstrated by the polymerase chain reaction. Am J Clin Pathol. 1991; 96:219-27.

87. Mathiak M, Warneke VS, Behrens HM, Haag J, Boger C, Kruger S, Rocken C. Clinicopathologic Characteristics of Microsatellite Instable Gastric Carcinomas Revisited: Urgent Need for Standardization. Appl Immunohistochem Mol Morphol. 2017; 25:12-24. doi: 10.1097/ pai.0000000000000264.

88. Lim H, Park YS, Lee JH, Son DH, Ahn JY, Choi KS, Kim DH, Choi KD, Song HJ, Lee GH, Jung HY, Kim $\mathrm{JH}$, Yook JH, et al. Features of Gastric Carcinoma With Lymphoid Stroma Associated With Epstein-Barr Virus. Clin Gastroenterol Hepatol. 2015; 13:1738-44 e2. doi: 10.1016/j.cgh.2015.04.015.

89. Cheng N, Hui DY, Liu Y, Zhang NN, Jiang Y, Han J, Li HG, Ding YG, Du H, Chen JN, Shao CK. Is gastric lymphoepithelioma-like carcinoma a special subtype of EBV-associated gastric carcinoma? New insight based on clinicopathological features and EBV genome polymorphisms. Gastric Cancer. 2015; 18:246-55. doi: 10.1007/s10120-014-0376-9.

90. Gutierrez MI, Raj A, Spangler G, Sharma A, Hussain A, Judde JG, Tsao SW, Yuen PW, Joab I, Magrath IT, Bhatia $\mathrm{K}$. Sequence variations in EBNA-1 may dictate restriction 
of tissue distribution of Epstein-Barr virus in normal and tumour cells. J Gen Virol. 1997; 7:1663-70. doi: 10.1099/0022-1317-78-7-1663.

91. Forman D, Bray F, Brewster DH, Gombe Mbalawa C, Kohler B, Piñeros M, Steliarova-Foucher E, Swaminathan R, Ferlay J, editors (2013) Cancer Incidence in Five
Continents, Vol. X (electronic version). Lyon: International Agency for Research on Cancer. Available from: http://ci5. iarc.fr. accessed 2017-05-24. 